\title{
Asymmetric Addition of Bis(homoally)zinc to the Propargyl Aldehyde Dicobalt Hexacarbonyl Complexes in the Presence of Chiral Disulfonamide Followed by Pauson-Khand Reaction"
}

\author{
Andreas Stumpf, Sung Hee Hwang, Jin Sung Kim, and Nakcheol Jeong ${ }^{\star}$ \\ Departmen of Chemistry and Division of Molechlar Engineering and Chemisiry, Korea Liniversity, Seoul 136-701, Korea \\ Received September 16, 2004
}

Key Words : Pauson-Khand reaction, Propargyl aldehyde dicobalt hexacarbonyl, Asymmetric addition, Bis(homoallyl)zinc

The preparation of the optically active secondary propargyl alcohols has been a subject of intensive researches.' These include the addition of dialkynylzine or mixed alkyl alkynylzinc to aldehydes by the aid of chiral ligands in moderate to excellent ees, ${ }^{2,3}$ and the reduction of alkynyl ketones in relatively high enantioselectivity. ${ }^{+}$And an alternative approach by the addition of dialkylzinc to propagyl aldehyde in the presence of catalytic amount of the chiral ligands has not been satisfactory until recent years. ${ }^{5.6}$ This relatively poor efficiency was attributed to smaller steric differences. Exaggeration of the steric environment of alkyne by introducing temporary protecting group would be the choice of trials to increase the enantioselectivity. Dicobalt carbonyl moiety on triple bond had been often used to improve enantioselectivity in this line. Roush and Park demonstrated a significant improvement of enantioselectivity in the reactions of homopropargyl aldehyde with a stoichiometric amount of allylborane by introducing dicobalt hexacarbonyl on alkyne moiety. ${ }^{7}$ Nicholas also studied the reaction of the cobalt-complexed propargyl aldehydes with chiral ( $\gamma$-alkoxyallyl)borane under the same condition and showed high enantioselectivities as well as diasteroselectivities. ${ }^{8}$ Recently, Pericas showed that asymmetric diethylzinc addition to the same complex by the aid of chiral aminoalcohol ligand provided virtually single enantiomers of secondary propargyl alcohol. ${ }^{9}$

At the same time, we also envisioned that this approach would give not only high enantioselectivities, but also an efficient way for the more elaborated systems. For example, the asymmetric addition to dicobalt carbonyl complexed propargyl aldehydes by analogs higher than ethyl, such as bis(homoallyl)zinc and higher analogs, would allow products which can be subjected to Pauson-Khand reaction (PKR here after) afterward.

The subsequent reaction can be run separately or in onepot, and would furnish the optically active bicyclic $[3,3,0]$ or $[4,3,0]$ compounds. These bicyclic compounds can be served for the synthesis of various natural products in optically

\footnotetext{
"This paper is dedicated to Professor Yong Hac Kim for his distinguished achievements in chemistry.

Corresponding Author. Fax: -82-2-3290-3121: Tel: -82-2-3290-

3136: e-mail: njeongrakerea.ac.kr
}

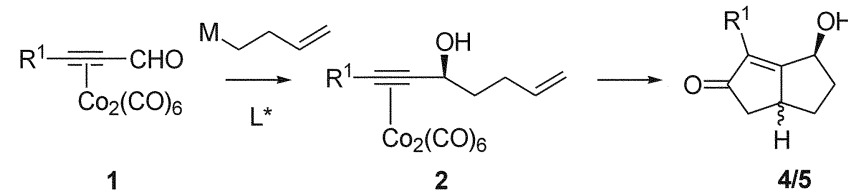

Scheme 1

active form. $^{10}$ (Scheme 1)

Herein, we would like to report the results of our preliminary study about the reactions of dicobalt complexed propargyl aldehydes and dialkylzinc in the presence of chiral catalysts.

We first examined the scope of the compatibility of these dicobalt hexacarbonyl complexes of propargyl aldehydes with currently available asyınmetric 1,2-addition conditions. Either amino alcohol catalysts ${ }^{2}$ or TADDOL catalysts ${ }^{11}$ together with diethylzinc proved to be inappropriate for this tranformation in our hand. ${ }^{9}$ Low yield (6-10\%) of the metal complexes of propargyl alcohol was obtained along with some of the unreacted starting materials (10-20\%). Most of the complexes had been destroyed during the reaction. However, a catalyst prepared by mixing of chiral disulfonamide $(0.2 \mathrm{eq})$ and titanium tetra-isopropoxide (1.2 eq) turned out to be the choice of the reaction.

We adapted the procedure developed by Ohno" and generalized by Knochel. ${ }^{12}$ The catalytic species was prepared by mixing of (1S, 2S)-(+)-cyclohexyl disulfonamide (6) and freshly distilled titanium tetra-isopropoxide in $n$-hexane followed by heating at $60^{\circ} \mathrm{C}$ for $2 \mathrm{~h}$. After cooling the resultant catalytic species to $-78^{\circ} \mathrm{C}$. dialkylzinc and the corresponding aldehyde were added. The resulting mixture was allowed to warm to $-25^{\circ} \mathrm{C}$ over $12 \mathrm{~h}$. Metal complexed propargyl aldehydes smoothly reacted to give the corresponding propargyl alcohol complexes in high yields (72$98 \%)$ and excellent enantioselectivities $(\% 93 \%)$ after usual work-up ( Jable 1).

The metal complexes (1) were demetalated by using ammonium cerium(IV) nitrate (CAN) in methanol and optical purities of the propargyl alcohols (3) were found to be better than $90 \%$ ee for all examined cases.

The overall efficiency of the reaction of metal complex in terms of chemical yields and enantioselectivities are apparently better than that with metal free propargyl aldehyde. ${ }^{6.9}$ Especially, this approach allowed to have a reliable process 
Table 1. Asymmetric addition of dialkyline in the presence ol chiral bis(sulphonamide) liand and titanium alkoxide

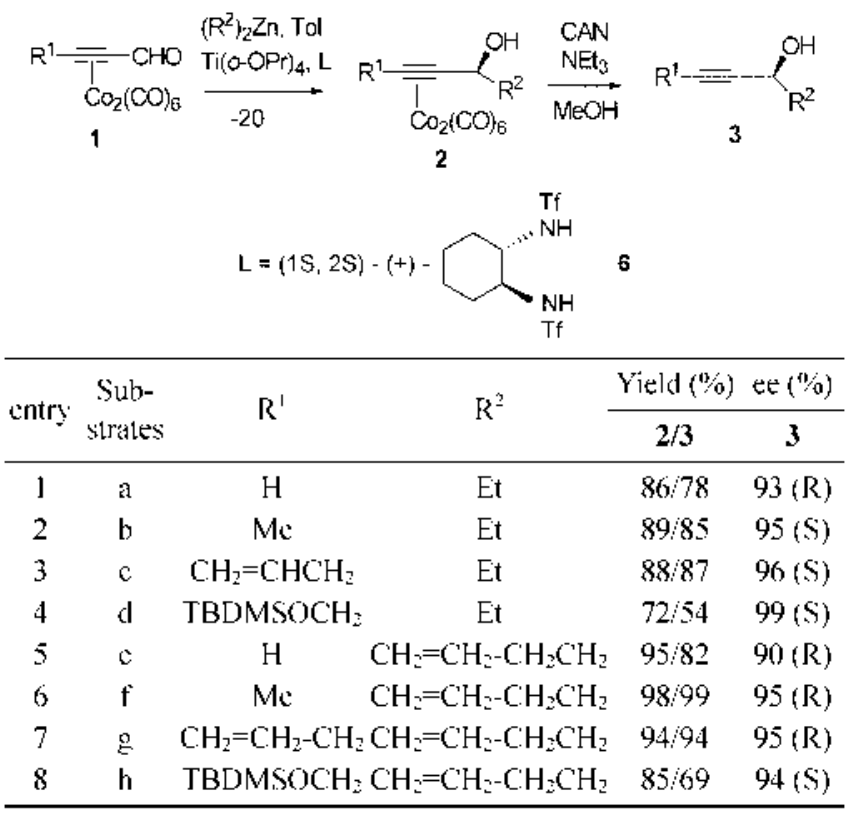

even for the volatile low molecular weight propargyl aldehydes, such as propynal (entry 1 in Table l).

Subsequent l'auson-Khand reaction of the homoallylated propargyl alcohol complexes (2e-2h) were studied under the promoter assisted reaction conditions. All of the substrates derived from the 1,2-addition of bis(3-buten-|-yl)zinc underwent P'KR smoothly. 'TMANO promoted PKR of the resultant propargyl alcohol complexes provided the corresponding bicyclic compounds in high yield as a mixture of diastereomers. The resultant mixture of diastereomers except entry 4 in lable 2 were transformed into the MOM protected derivatives for facile separation and analysis. The results are summarized in lable 2 .

Diastereoselectivity is dependent on the substituent on terminal alkyne, which range from $1: 1$ for $H$ to $7: 1$ for allyl under our condition, but has not been optimized. Optical purity of each diastereomer was measured by chiral $\mathrm{GC}$ analysis and reflected that of propargyl alcohol obtained

Table 2. Pauson-Khand reaclion of the resulting propargyl alcoholcobalt carbonyl complexes (2)

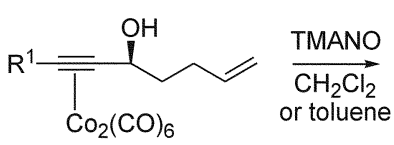

2

\begin{tabular}{|c|c|c|c|c|}
\hline entry & $\mathrm{R}^{\prime}$ & $\begin{array}{l}\text { combited } \\
\text { yield }(\%)\end{array}$ & $\begin{array}{c}d s \\
4: 5\end{array}$ & $\begin{array}{c}\text { ee }(\%) \\
4 / 5\end{array}$ \\
\hline I & $I I(e)$ & 56 & $1.1: 1$ & $89: 89$ \\
\hline 2 & $M_{e}(f)$ & 72 & $7.5: 1$ & 95,95 \\
\hline 3 & $\mathrm{C}_{2} \mathrm{l}_{2}=\mathrm{C} . \mathrm{ICCH} \mathrm{I}_{2}(\mathrm{~g})$ & 71 & $6.7: 1$ & 9595 \\
\hline 4 & II3I)MS()(II, (h) & 66 & $4: 1$ & 9494 \\
\hline
\end{tabular}

from nucleophilic addition directly.

In one case we carried out the reaction all the way in one pot operation. we were able to obtain the corresponding product in reasonable yield and diastereoselectivity.

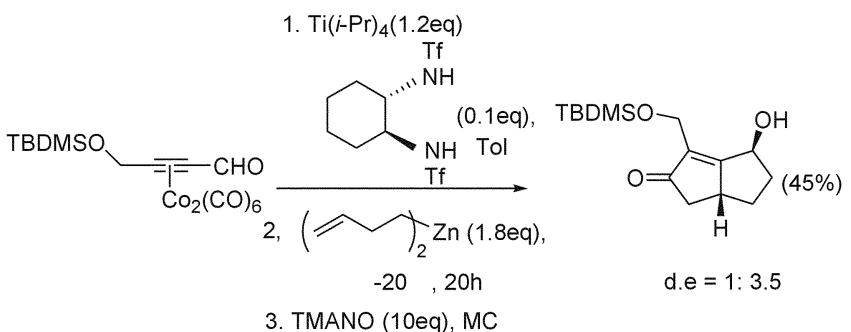

In summary, we were able to find out the reaction condition of the 1,2-nucleophilic addition to the dicobalt hexacarbonyl-propargyl aldehydes, which allowed high enantioselectivity and chemical yield. And subsequent l'auson-Khand reaction of the resultant products (2-e $\cdots \mathbf{2}-\mathbf{h}$ ) provided the bicycliccompounds ( 4 and 5 ) efficiently. The application of this process to the natural products synthesis is underway.

Acknowledgement. Financial support of this work from the $\mathrm{DFG}$ in the form of a research stipend to A.S. is gratefully acknowledged. And funding by CMDS and from KOSEF (grant No. R02-2002-000-00128-0 of the Basic Research Program) are also appreciated. JSK is grateful to BK2 l fellowship.

\section{Notes and references}

1. (a) Ojima l. Is Catabtic Aspmmetric Sinthesis: Maruoka. K.. Yamamoto. II.. Fds.: VCII Publishers: New York. 1993: p 413, (b) Schelfold. R. In Modern Symthetic Hethods: Noyori. R.. Kitamura. M.. Isds.: Springer Verlag: 1989: Vol. 5. p 115.

2. Corey. E. I.: Crimprich. K. A. J .1m. Chem. Soc. 1994. /16.3151. and leading references are therein.

3. (a) Plu. L.: Yu. H.-B. Chen. Rev 2001. 101. 757. (b) Li. X.: Lu. G.: Kwok, W. II. Chan, A.S. C.J. An. Chem. Soc. 2002. 124. 126.36. and leading references are therein.

4. (a) Noyori. R.: Tomino. I.: Taumolo. Y.: Nishizawa M. $J \mathrm{dm}$. (he'm. Soc. 1984. 106. 6709. (b) Parker. K.: Ledeboer. M. W. .J. Org. Chem. 1996.61.3214.

5. (a) Soai. K: Niwa. S. Chemist? Lett 1989. 481. (b) Niwa S.: Soai. K. J. Chem. Soc., Pesin Trams. / 1990.937. (c) KitajimaL II.: Ito. K.: Aoki. Y.: Katsuki. T. Bufl. (hem. Soc Jpn. 1997. 70. 207. (d) I luang. W.-S.: I lu. Q.-S.: Pu. I.. J. Org. (hem. 1998. 63. 1364.

6. (a) Lutjens. H.: Nowotry. S.: Knochel. P. Tetratredron. 1.ronmetry: 1995. 6. 2675. (b) Secbach. D.: Bcck. A. K.: Schmidt. B.: Wang. Y. M. Tetratredon 1994. 50. 4363.

7. (a) Roush. W. R.: Park. J. C. Terthedron Leti. 1991, 32, 6285. (b) Roush. W. R.: Park. I. C.J. Org. (hem. 1990. 55. I143. (c) Roush. W. R.: P'ark. J. C. Tetrahedron Lett. 1990. 3l. 4707.

8. (a) Ganesh. P.: Vicholas. K. M. J. Org. (hem. 1993. 58.5587 . (b) Ganesh. P.: Nicholas. K. . . J. Org. Chem. 1997. 62. 1737.

9. Fontes. M.: Verdaguer. X.: Sola. L.: Vidal-Ferran. A.: Reddy. S.: Rieris A.: Pericas, M. A. Otg. Lett. 2002. 4. 2381.

10. Mehtic (i.: Srikrishna. A. Chem. Rev 1997.97.671.

11. Yoshioka. M.: Kantakita I.: Ohno. M. Tetrahedron lett. 1989. 30. 1657.

12. Rozema. .. I.: Achyutharao. S.: Knochel. P. J. Org. Chem. 1992. 57.1956. 